\title{
La música de Brahms en el pensamiento de Ludwig Wittgenstein
}

Brahms's Music in Ludwig Wittgenstein's Philosophy

Vicente Ordóñez-Roig ${ }^{\otimes}$

Universidad Jaume I - España

Recibido: 2014-04-30

Envío a pares: 2014-04-30

Aprobado por pares: 2014-05-27

Aceptado: 2014-06-01

Pensamiento y Cultura | ISSN: 0123-0999 | elSSN: 2027-5331

pensam.cult | Vol. 17-1 | Junio de 2014 | pp. 73-94

DOI: 10.5294/pecu.2014.17.1.4 


\section{La música de Brahms en el pensamiento de Ludwig Wittgenstein}

Resumen: El objetivo de este artículo es estudiar las huellas que la música y, sobre todo, la música de Brahms, dejó en el pensamiento de Wittgenstein. Con este fin, se analizarán las impresiones que le merecían a Wittgenstein la música clásica y moderna, dedicando especial atención a las comparaciones que establece entre las obras de Brahms y las de otros compositores, especialmente Mendelssohn y Bruckner. En este contexto, se reflexionará sobre la función que, en opinión de Wittgenstein, podría desempeñar la música clásica como medio para expresar valores o principios éticos.

Palabras clave: Comprensión, cultura, música clásica, explicación, genio.

\section{Brahms's Music in Ludwig Wittgenstein's Philosophy}

Abstract: The aim of this paper is to consider in detail the role music played in Wittgenstein's thought, more specifically the music of Brahms. To this end, the author studies Wittgenstein's impressions on classical and modern music. Special attention is given to Wittgenstein's comparison between the works of Brahms and others composers' such as Mendelssohn's or Bruckner's. In addition, the author reflects on the function that classical music could play as a means to express values or ethical principles.

Key words: Understanding, culture, classical music, explanation, genius. 


\section{Introducción}

El número de mayo de 2011 de la revista vienesa Österreichische Musikzeitschrift está dedicado casi en su totalidad a celebrar el centenario de la muerte de Gustav Mahler. El editorial de la publicación lleva por título "Umkämpft, verdrängt, geliebt»: disputado, desplazado, amado Mahler. En él se analiza la controvertida figura del compositor bohemio; la crítica feroz que causaron sus exploraciones de nuevos territorios sonoros; el rechazo de sus sinfonías más innovadoras; el maltrato que sufrió por parte de editores, administradores y prensa musical, en especial de críticos como Robert Hirschfield, Rudolf Louis, etc., quienes calificaron su música de «broma fúnebre», «impotente», «vulgar», «banal»; la herida abierta que le supuso su condición de apátrida - Mahler, ciertamente, representa el paradigma del extranjero retratado por Edmond Jabés: un tipo humano que suscita toda clase de suspicacias y recelos a su alrededor, que está fuera, que guarda las distancias con las comunidades, colectividades, asociaciones o agrupaciones, que es la otreidad absoluta o l'étrange-je; etc. No es este el lugar para analizar los pormenores de la vida y obra de Mahler. Si traemos a Mahler a colación, sin embargo, es porque supone el primer atisbo de decadencia musical tal y como la entiende Ludwig Wittgenstein. En la miscelánea o colección de notas y observaciones de Wittgenstein editadas por Georg Henrik von Wright (Vermischte Bemerkungen u Observaciones diversas. Cultura y valor en su edición en español), se encuentra, en una entrada del año 1948, la siguiente reflexión:

\footnotetext{
"si es verdad, como creo, que la música de Mahler no tiene valor, entonces se plantea la pregunta de lo que él debió haber hecho con su talento según mi opinión. Pues es evidente que para hacer esta mala música se necesita una serie de talentos muy raros. ¿Debió, por ejemplo, escribir sus sinfonías y quemarlas? ¿O debió contentarse y no escribirlas? ¿Debió escribirlas y ver que no valían nada? Pero, ¿cómo podía verlo? Yo lo veo porque puedo comparar su música con la de los grandes compositores" (Wittgenstein 2009d, 628).
} 
Siendo que Mahler posee lo que Wittgenstein denomina talento, ¿por qué su música carece de valor? ¿Es porque, como Wittgenstein a menudo se reprocha a sí mismo siguiendo en esto a Weininger, para crear se necesita de esa cualidad sintética y gelatinosa que denomina «genio»? Pero, ¿cómo juzgar la obra de un compositor? Porque el juicio de una pieza musical es un juicio estético. Y, a tenor de lo que Wittgenstein expone en el Tractatus, la estética, como la ética, no se deja expresar (6.421). ¿Cómo juzgar, por tanto, cómo valorar las producciones de un compositor, sus sinfonías, canciones, sonatas, cuartetos? ¿Contraponiéndolas, comparándolas con las de otros compositores - con los «grandes»—? Examinemos cómo penetra la música en el pensamiento de Wittgenstein tomando como referente la obra de uno de esos grandes compositores a los que veladamente alude: Johannes Brahms.

\section{El declinar del espíritu en la música}

En una carta de Sergei Prokofiev a Paul Wittgenstein fechada en 1931, el compositor ruso intenta entrever cuál será la impresión que le causará al pianista vienés la pieza que ha creado para él (Concierto para piano número 4). Arguye que, ante los pasajes que le puedan resultar difíciles de comprender y digerir, debe guardar una cierta distancia. El problema, sostiene, es que Paul Wittgenstein no es sino un músico del siglo XIX; él, Prokofiev, del XX (Waugh 2009, 189). Esta misma apreciación es válida para su hermano Ludwig. La música concluye para Ludwig Wittgenstein en el siglo XIX con la obra de Brahms y, en cierta medida, con la del organista ciego y protegido de la familia Josef Labor. Dejando a un lado las composiciones de este último, Brahms es, junto con Haydn, Mozart, Beethoven y Schubert, el último de los grandes maestros que Wittgenstein respeta y admira. Frente al estilo perfilado y estructurado, frente al rigorismo formal, síntesis de clasicismo y romanticismo, de Brahms, Mahler y, en general, la música moderna, despierta en Wittgenstein rechazo, desprecio, minusvaloración. ¿Por qué? Para entender esta cuestión hay que prestar atención a lo que Wittgenstein entiende por cultura. La cultura, escribe en el proyectado prólogo a las Observaciones filosóficas, es una suerte de "organización que señala su lugar a todo 
el que pertenece a ella, lugar en el que puede trabajar dentro del espíritu del todo, y su fuerza puede medirse justamente por su resultado en el sentido del todo" (Wittgenstein 2009d, 568). Palpita en esta primera aproximación el concepto de cultura tal y como Spengler lo concibe en La decadencia de Occidente. Esto es, la cultura como estado orgánico, como entidad biológica independiente y autónoma, como forma goethiana que alcanza su fin más perfecto en virtud de su propio desarrollo o ciclo vital - alle Gestalten sind ähnlich, und keine gleichet der andern, canta Goethe en la Metamorfosis de las plantas: todas las formas son parecidas y ninguna es igual a la otra; sin embargo, todas muestran idéntico aspecto (Goethe 1960, 543). La cultura es esa misma forma que no sólo orienta a quienes pertenecen a ella, sino que aglutina la energía de sus integrantes y la reconduce desde su individualidad hacia una dimensión nueva, diferente, una dimensión en la que los distintos caracteres que la componen quedan subsumidos en una unidad mayor. Al determinar morfológicamente la estructura de la cultura, Spengler introduce en su secuencia lógica y desarrollo, no sólo los momentos de superfluidad y plenitud, sino también de impotencia, extinción, crisis, ocaso. De hecho, "hoy vivimos el decrescendo" (Spengler 1989, 529). Este momento descendente, contrapartida o lado opuesto de la gran cultura, es a lo que Wittgenstein apunta con el término Unkultur o anticultura: "En la época de la anticultura se hacen pedazos las fuerzas, y la fuerza del individuo es desaprovechada por las fuerzas opuestas y las resistencias" (Wittgenstein 2009d, 568). Wittgenstein señala que esto poco o nada tiene que ver con un juicio de valor como explica en sus Diarios de guerra, lo que desea Wittgenstein es "informar acerca del mundo que yo me he encontrado" y no otra cosa (Wittgenstein 2009a, 109). Por ello, constata que el suyo es un tiempo de desorientación en el que el sujeto moderno carece de la estructura necesaria para que su acción sea una acción plena de sentido.

La música, en este contexto, destaca entre las demás artes por hallarse sometida a un proceso de total desintegración. Esto es relevante en la medida en que, en buena parte de la civilización occidental, «cultura» es sinónimo de cultura musical. Es hacia finales del siglo XVIII y, principalmente, a partir el estallido del movimiento romántico, 
que en los países centroeuropeos de raigambre germánica corresponde a la expresión musical la superioridad entre todas las artes. Hay una línea multiforme y heterogénea que va de la música vocal de Palestrina al constructivismo polifónico de Frescobaldi y a la obra contrapuntística de Bach y, desde ahí, llega hasta el Réquiem alemán de Brahms o al Parsifal wagneriano. Sólo a través de esas formas sonoras en movimiento, sólo por medio de un lenguaje trascendental como el musical es uno capaz de acercarse hasta lo indeterminado, hasta la pureza transparente de los sentimientos o del absoluto — según defenderán los partidarios de la música programática o de la música pura. En el caso de Wittgenstein, la influencia de la música en su vida es decisiva. Su estudiante y amigo Maurice Drury explicaba que al observar a Wittgenstein escuchar música uno podía comprender que constituía algo muy central y profundo en su vida. "Nunca olvidaré con que insistencia citaba el juicio de Schopenhauer, a saber: que el mismo mundo es la música" (Nyíri 1986, 186). Asimismo, Allan Janik y Stephen Toulmin señalan que para los Wittgenstein en cuanto clan "la cultura fue ante todo cultura musical" (Janik y Toulmin 1983, 217). Y es cierto. Porque la música era, no sólo un entretenimiento esporádico o pasajero del que toda la familia participaba en la Musiksaal sino, fundamentalmente, la manera como los Wittgenstein se comunicaban entre sí. Por tanto, no es la música el arte más refinado que pueda existir: la música es en sí la más alta forma de vida, una vida en la que, al menos para los Wittgenstein, la patología se entrelaza con la hipersensibilidad, con la pasión desbocada y el anhelo de indulgencia, con la emoción.

Es en este ambiente impregnado de cadencia, armonía y ritmo que Wittgenstein acusa, quizá con mayor intensidad, la profunda crisis que afecta al espíritu occidental del siglo XX. Únicamente a partir de la materialización del declinar de la cultura puede entenderse que, en la civilización europea y americana, el lugar privilegiado que otrora ocupara la música sea ahora altar del deporte, la ciencia, la industria, la música de baile, la arquitectura, la ingeniería, etc. Las consecuencias son catastróficas. Y lo son porque afectan a la estructura óntica del sujeto moderno mismo. Sólo así se explica la insistencia de Wittgenstein por desenmascarar lo que para él no es, no puede ser sino fraude, un arte 
mezquino y espurio que degenera de su origen o naturaleza. En sus Diarios de los años treinta, en una entrada correspondiente al 27 de enero de 1931, puede leerse:

"La música de épocas pasadas corresponde siempre a ciertas máximas sobre lo bueno y lo malo de su misma época. Así reconocemos en Brahms los principios de Keller, etc., etc. Y por ello la buena música creada hoy o hace poco - moderna, pues - tiene que parecer absurda, ya que si corresponde a cualquiera de las máximas que se declaran hoy tiene que ser una porquería. Esto no es fácil de comprender pero es asi'” (Wittgenstein 2009c, 218).

Una música que surge sin sustrato espiritual, sin fondo ni trasfondo ético-estético, sin una tradición que la sustente - alejada en demasía de la variación que se extiende sin interrupción o de la música instrumental pura, íntima, compleja, delicadamente profunda- es absurda y mendaz, una cacofonía que se esfuerza por alcanzar una existencia tan voluminosa que termina por desconcertar. Representa para Wittgenstein la música del siglo XX, en cierto modo, la cicatriz purulenta de los apuntes dejados por los grandes maestros ya desaparecidos. ¡Qué lejos queda la alusividad y la circunspección de la melodía que no quiere expresarlo todo, sino más bien sugerir! ¡La irracionalidad antojadiza y voluble que los románticos llamaban Humoresque! ¡El vagabundeo entre el yo y el mundo que es pura negación y relatividad! ¡La corriente continua de notas del Perpetuum mobile! ¡Las raíces poéticas de una música que germina en la tierra de Goethe, Hebel, Schiller, Hölderlin, Uhland, Möricke o Keller! "En la época de la civilización, de la anti-cultura, en la que el espíritu se retira", afirma Vicente Sanfélix, en esta época "las artes decaen y las naturalezas auténticas y fuertes, a través de las cuales se expresa el valor de lo humano, persiguen un interés meramente privado en el contexto de una sociedad de masas" (Sanfélix 2005, 293). Si la cultura que cobija al espíritu de la civilización europea y americana está en quiebra, la música que resulta de esa civilización no puede sino ser expresión y máxima realización de esa misma ruptura interior. 


\section{Comprender a Brahms}

Es conocida la repulsión que provocaba la vida académica a Wittgenstein, que se jactaba públicamente de no haber leído ni una sola línea del corpus aristotelicum. Si la poca filosofía que decía haber absorbido le parecía excesiva, mostraba un interés sincero por las películas del oeste, por la poesía romántica alemana, la jardinería o las revistas detectivescas norteamericanas - la Detective Story Magazine era, al parecer, su favorita. Estas revistas se las proporcionaba regularmente su antiguo alumno Norman Malcolm. En el curso de la correspondencia entre ambos parece ser que Malcolm envió, no su revista de detectives predilecta, sino otra diferente. Wittgenstein le amonestó: "me pregunto por qué intentaste ser original en lugar de atenerte a lo bueno, antiguo y ya puesto a prueba” (Malcolm 2001, 87). Más allá de la anécdota, la sentencia resume certeramente la actitud de Wittgenstein respecto a la música. En una anotación de su Diario de 1931 expone lo siguiente: "cuando los últimos grandes compositores escriben de improviso en desarrollos armónicos simples se decantan por la progenitora de su estirpe". Y añade: "precisamente en esos momentos (cuando los demás conmueven al máximo) Mahler me parece especialmente insoportable \& entonces siempre me gustaría decir: pero si eso sólo lo has escuchado de los otros, eso no te pertenece (realmente) a ti" (Wittgenstein 2009c, 232). Wittgenstein alaba los desarrollos armónicos simples de los últimos grandes compositores porque la alternancia de disonancias y consonancias, las modulaciones que se suceden en sus piezas musicales, se producen en tonalidades más o menos próximas: la referencia a la tonalidad principal nunca se pierde de vista. No será sino a partir de Wagner y, principalmente, de Mahler y Strauss, que el concepto de tonalidad entre en crisis - aunque ya en la obra de Mozart, Schubert y Beethoven se producen alternancias tan vertiginosas que las nuevas tonalidades apenas entran en contacto. También en Brahms: el Cuarteto de cuerda en do menor, Op. 51 sería buena muestra de ello. Sin embargo, que la música moderna pero, sobre todo, que en la música de Mahler se den tales alejamientos de la tonalidad fundamental de suerte que los desarrollos armónicos resultan del todo crípticos y velados, le 
parece a Wittgenstein insoportable. Es como si sus piezas recorriesen al azar incalculables posibilidades movidas por un cromatismo que lleva a la disolución de la forma en lugar de respetar eso bueno, antiguo y ya puesto a prueba ${ }^{1}$. Porque la música moderna no es perifrástica sino elíptica: si evita el circunloquio, omite en la composición las referencias necesarias para la recta construcción musical sin que resulte claro el sentido del conjunto. La música de Brahms es ya otra cosa. El maestro de Hamburgo, alejado de la opulencia y los excesos de la nueva escuela alemana de Weimar, entronca con la tradición clásica sin convertirse por ello en un mero reproductor. Desde la óptica de Wittgenstein, Brahms bien podría ser a la música lo que Aliosha Karamázov a la moral: pureza cristalina, rigor, claridad translúcida, integridad total. Así queda, al menos, insinuado en sus apuntes de los años treinta, donde un apasionado Wittgenstein escribe: "el poder avasallador de Brahms; la fuerza del pensamiento musical de Brahms" (Wittgenstein 2009d, 585/587). Las composiciones de esta suerte de héroe joven e ideal extraído de un relato de Jean Paul, como fue caracterizado por Hanslick, suponen la culminación del modelo clásico tal y como lo entiende Wittgenstein. Mas es un clasicismo arrollador. Es Schönberg el primero que, en su ensayo Brahms el progresivo, ha puesto el acento en las innovaciones introducidas por el compositor alemán en el lenguaje musical: "la asimetría - combinación de frases de distinta extensión, número de compases indivisible por ocho, por cuatro y hasta por dos; es decir, imparidad de número de compases - y otras irregularidades, aparecen ya en las más tempranas obras de Brahms" (Schönberg 1984, 416). Es poco probable que Wittgenstein fuera ajeno a las peculiaridades del mundo sonoro brahmsiano. En sus Memorias, el dramaturgo Max Zweig cuenta que conoció a Wittgenstein durante su estancia en la ciudad morava de Olmütz - en concreto en casa de Paul Engelmann, denominada no sin cierta ironía el Palacio de Mauritzplatz. Wittgenstein fue enviado en el

1 Las consideraciones de Wittgenstein sobre la música de Mahler, no obstante, deben ser tomadas con cautela. John King recuerda que: "él [Wittgenstein] tenía un sorprendente retrato de Mahler, pero como yo apenas conocía a Mahler o sus composiciones, él solo mencionó que uno necesitaría saber mucho de música, su historia y desarrollo para entenderlo" (Wittgenstein 1981, 86). 
ecuador de la Primera Guerra Mundial con el fin de realizar un curso de oficial. Zweig explica que presenció una vez una conversación entre Wittgenstein y el pianista y concertista Fritz Zweig sobre la "semejanza y diferencia de la música de Schubert y Brahms; pero la comprensión de esa charla presuponía un conocimiento tan profundo de la música que no conseguí seguirla" (Zweig 1987, 78). Una persona educada en la Bildungsbürgertum vienesa del XIX, con una fina sensibilidad musical, dotada, además, de oído absoluto como Wittgenstein, una persona así es capaz de penetrar en el núcleo de la música de Brahms y entrever sus resortes y matices. En sus Diarios se encuentra la siguiente anotación:

"las composiciones hechas al piano, en el piano, las compuestas pensando con la pluma y las compuestas sólo con el oído interior, deben tener un carácter completamente distinto y producir una impresión totalmente distinta.

Creo que Bruckner componía sólo con el oído interior e imaginando la interpretación por la orquesta; Brahms, en cambio, con la pluma. Desde luego esto se expresa de un modo más simple de lo que es en realidad. Pero con ello se encuentra una característica" (Wittgenstein 2003, 85).

Es interesante notar cómo Wittgenstein relaciona la dificultad de la composición con la aridez de la escritura musical. Que Bruckner componga con el oído interior no quiere sino decir que es capaz de aprehender gracias a la imaginación reproductora los sonidos que circundan su fantasía. Esta experiencia subjetiva se aleja de la experiencia de componer una pieza musical teniendo entre las manos una libreta de pentagramas y algo para escribir en ella: si la primera busca la efectividad y el deslumbramiento, la segunda exige de una concentración y un rigor exhaustivos. Por ello Wittgenstein defenderá que las composiciones de Brahms son alambicadas, indeterminadas, abstractas. Si la música de Beethoven o Schubert puede ser utilizada por la industria cultural (algo a lo que recurren sistemáticamente los grandes estudios cinematográficos), difícilmente ocurrirá lo mismo con la música de Brahms: su aspereza y severidad tienen un 
sabor acre próximo al sabor de la verdad, lo que dificulta enormemente su comprensión. Pero, ¿por qué resulta difícil entender la música de Brahms? ¿Dónde radica su abstracción, fuerza o vigorosidad? Probablemente, la música ilustra mejor que ningún otro arte la complejidad que lleva aparejada su comprensión. En el contexto de una discusión entre Moritz Schlick y Wittgenstein en torno a cuestiones de ética teológica, Ray Monk reproduce unas palabras de aquél en las que indaga si explicar una pieza musical es o no posible: "de manera parecida, hay que cerrar cualquier camino que conduzca a una explicación del valor estético. ¿Qué tiene valor en una sonata de Beethoven? ¿La secuencia de las notas? ¿Los sentimientos de Beethoven cuando la compuso? ¿El estado de ánimo que provoca al escucharla? "Yo contestaría", decía Wittgenstein, "que, me digan lo que me digan, lo rechazo, y no porque la explicación sea falsa, sino por ser una explicación"2" (Monk 1997, 286). Habituados como estamos a que la comprensión sea una acción ligada al fenómeno de la Erklärung o explicación, la ruptura de ese nexo causal desconcierta en primera instancia. ¿Cómo dar a conocer las causas o motivos que hagan posible el recto juicio de una obra de arte? El intento de establecer una serie de pautas explicativas que constituyan algo así como el andamiaje de la comprensión adecuada es, probablemente, una completa quimera. En el terreno del lenguaje esa misma comprensión nos pasa desapercibida: creemos no sólo comprenderlo sino dominarlo en tanto usuarios de una lengua. Mas el lenguaje es, como Wittgenstein afirma, «un laberinto de caminos» (Investigaciones filosóficas $\$ 203$ ). Y si aceptamos, con Borges, que un laberinto es una casa labrada para confundir a los hombres, el lenguaje mismo adquiere la forma de una encrucijada en la que uno se pierde sin ser todavía consciente de su propia pérdida. Entonces, ¿cómo estar seguro de que se entienden las Variaciones Goldberg, la Heroica, los ballets de Stravinski o, más allá, la Symphony for improvisers de Don Cherry? Al explicar a sus alumnos de Cambridge el forcejeo que mantuvo con la poesía de Klopstock, Wittgenstein declara:

2 Como negativo al punto de vista de Wittgenstein podría traerse a colación la observación de Adrian Leverkühn: «apariencia y juego tienen hoy ya en contra la conciencia del arte. $\mathrm{El}$ arte quiere dejar de ser apariencia y juego. Aspira a ser conocimiento y comprensión (Erkenntnis)» (Mann 2009, 258). 
"tomemos la cuestión: «¿Cómo habría que leer la poesía? ¿Cuál es el modo correcto de leerla?» (...). Descubrí que el modo de leerlo era acentuar su metro anormalmente. Klopstock ponía comienzo de sus poemas. Cuando leí sus poemas de este nuevo modo dije: «Ah, ahora sé por qué hizo esto». ¿Qué había sucedido? Yo los había leído y me había aburrido bastante, pero cuando los leí de ese otro modo especial, con mucha atención, me sonreí y dije: «Esto es grande», etc. (...). Al leer esos poemas hacía gestos y ponía expresiones faciales que se dirían gestos de aprobación. Pero lo importante fue que leí los poemas de modo enteramente diferente, con mayor intensidad, y que dije a los otros: «iMirad! Así es como deben leerse»” (Wittgenstein 2009b, 658-659).

Gestos, expresiones faciales, gritos, movimientos, interjecciones... la comprensión de cualesquiera manifestaciones artísticas es un fenómeno ambiguo que se expresa de muy diversas formas. Los sonidos, como los conceptos, fluyen unos en otros. La clave estriba en captar las conexiones, las series, el cuerpo de significados. Retomando una de las cuestiones centrales del Tractatus, se podría afirmar que Wittgenstein señala que la comprensión de la música puede ser mostrada, no explicada o dicha: “ ¿Cómo debo explicar a alguien lo que significa "entender la música”? ¿Nombrándole las representaciones, percepciones de movimiento, etc., que tiene quien entiende? Más bien mostrándole (zeigt) los movimientos expresivos de quien entiende" (Wittgenstein 2009d, 631). En las Investigaciones filosóficas Wittgenstein se pregunta cómo entendemos una figura: "también aquí hay entender y no entender" (\$ 526). El pensador vienés no niega que no pueda haber comprensión: hay comprensión porque hay instrucción, adiestramiento en un determinado contexto, hábitos determinados por reglas que rigen su uso, juego de lenguaje. Ahora bien, que seamos capaces de comprender una proposición, una figura o un tema musical no implica que buena parte de su significado no pueda escurrírsenos por entre los dedos. Para que ello no ocurra, para captar la esencia de una pieza musical, una situación comunicativa cualquiera, una forma de expresión artística, etc., es necesario sumergirse en una determinada cultura. 
“Cómo se podría explicar en qué consiste 'la ejecución expresiva”? Seguro que no mediante algo que acompañe la ejecución. ¿Qué es, pues, conveniente para ese propósito? Cierta cultura, se podría decir. - Si a alguien se le ha educado en determinada cultura, $-\mathrm{y}$ después reacciona de tal o cual modo ante la música, se le puede enseñar el uso de la frase ejecución expresiva" (Wittgenstein 2009e, 764).

La música - ese lenguaje donde todo lenguaje concluye, en inspirada expresión de Rilke- es una experiencia que requiere de un ámbito concreto y de un escenario formativo muy específico para ser comprendida. ¿Por qué la música de Brahms tiene algo que otras músicas no tienen, entonces? Porque la música con la que Wittgenstein se identifica es aquella que dice algo; es capaz de expresar valores porque responde a necesidades espirituales generales de los seres humanos; permite estar en el mundo de una forma determinada, más orgánica y nutricia; etc. Desde la perspectiva de Wittgenstein, la música de Brahms despliega una serie de valores positivos fruto de su inserción en una determinada cultura cuyo ocaso, por otra parte, oscurece cada vez más su comprensión.

\section{Soles que se levantan y se ponen}

En las anotaciones de los cuadernos personales de Wittgenstein es frecuente encontrar el nombre de Brahms asociado al de otros compositores: Mendelssohn, Beethoven, Wagner, Bruckner, etc. En cierto modo, la música pura cincelada en la tradición clásica de Brahms se aproxima al conservadurismo romántico de Mendelssohn. Quien fue idolatrado y repudiado por igual. Si Schumann ve en él al restaurador de lo antiguo que condensa las cualidades del auténtico artista ideal, Wagner, en El judaísmo en la música, lo ataca con no disimulado desprecio: su esterilidad musical, sostiene, es el apogeo de la inconsistencia y la arbitrariedad. Mendelssohn representa mejor que ningún otro, quizá, el modelo de perfección clásica. Wittgenstein menciona que entre Brahms y Mendelssohn hay una patente afinidad, una relación familiar o Verwandschaft: "el parentesco al que me refiero podría expresarse diciendo que Brahms le da todo el vigor donde Mendelssohn lo dio sólo a medias. O: Brahms es 
con frecuencia un Mendelssohn sin faltas"(Wittgenstein 2009d: 583). Aquí Wittgenstein no hace sino repetir el argumento esgrimido por los detractores de Mendelssohn, que denuncian en su música la escasez de vértigo, de riesgo, de negatividad, de impulso hacia lo indeterminado. Mendelssohn carece no sólo del instinto primitivo, sino de la fuerza que caracteriza al artista puro. Porque "en todo gran arte hay un animal SALVAJE domado" (Wittgenstein 2009d, 600); y en Mendelssohn, como en Wittgenstein —según éste mismo admite- no lo hay. ¿Se encuentra en Brahms ese wildes Tier, ese animal salvaje enjaulado que define al artista puro? En alguna ocasión Wittgenstein relata a su círculo de amigos la profunda impresión que le causó escuchar a su hermano Hans interpretar sus composiciones al piano. Era tal la tensión creativa, que a Wittgenstein le parecía que esa imagen era la máxima expresión de la idea de genio. En su detallada biografía sobre Johannes Brahms, Max Kalbeck relata cómo, por casualidad, sorprendió en su residencia veraniega de Ischl a Brahms en plena tarea compositiva. A medida que se acercaba a la estancia en la que Brahms creaba sobre el piano una música fascinante, observaba sin ser observado. Mientras la obra se iba configurando "y la ejecución se volvía más apasionada, tanto más fuerte se alzaban los rugidos extraños, los gemidos y lamentos, que en el clímax de elevación musical degeneraban en ruidosos aullidos" (Kalbeck 1913a, 248). Esta imagen apasionada y colérica del genio de Brahms sería muy del gusto de Wittgenstein - y bien podría ser una muestra del gran arte que, contra Mendelssohn, Brahms sí poseería.

Si Brahms tiene algo de lo que Mendelssohn carece, no está del todo claro si, en opinión de Wittgenstein, Brahms puede ser considerado un genio. La idea de genio, topic central y recurrente en los autores del romanticismo, llegó a ser para Wittgenstein poco menos que una obsesión. Siguiendo en este punto las reflexiones de Weininger, en sus diarios Wittgenstein muestra un prejuicio racial sobre el asunto: "entre los judíos el "genio" sólo se encuentra en los santos. El mayor pensador judío no tiene sino talento. (Yo, por ejemplo)" (Wittgenstein 2009d, 580). Aunque fue educado en la tradición cristiana, Mendelssohn, como Wittgenstein, pertenecía a una antigua familia judía. A juicio de Wittgenstein, esas raíces constituían una pesada carga que lastraba profundamente 
el proceso creativo: difícilmente tendrían los judíos capacidad para el verdadero arte. Pero hay más. Wittgenstein sostiene que no debemos perder de vista la condición de posibilidad de la existencia del verdadero genio: la audacia, el coraje o arrojo -der Mut-. Mendelssohn era un compositor con talento, pero no era un músico dotado de una voluntad impetuosa y fuerte. En su música hay una carencia de energía y coraje tal que no puede hablarse en términos de genio. Pero entonces, ¿cuál es el paradigma del genio? ¿Quiénes son aquellos que, según Wittgenstein, tienen suficiente coraje, talento y carácter para ser considerados como auténticos genios? Aquellos cuyo ver no es sino un prever; cuyo decir no es sino un predecir; cuyo conocer es ya un preconocer; aquellos que escriben en el oscuro lenguaje de la profecía y a los que Wittgenstein se refiere como los verdaderos hijos de dios: Mozart y Beethoven (McGuiness 2008, 34). ¿Y Brahms? ¿Es él uno de los elegidos? La música de Brahms tiene tal capacidad de sugestión y potencia, que a punto estuvo de llevar a Wittgenstein a su propia aniquilación. Los intentos de suicidio de Wittgenstein son frecuentes y, de creer lo que él mismo insinúa en una evocación sobre su infancia, antes incluso de que sus hermanos Hans y Rudolph se quitaran la vida, Ludwig había barajado esa posibilidad a la temprana edad de diez u once años. En su ensayo Una lectura contra Shakespeare, Geroge Steiner explica que Wittgenstein confesó en una ocasión a Norman Malcolm "que el movimiento lento del tercer cuarteto de Brahms le había llevado dos veces al borde del suicidio" (Steiner 2001, 96). Una música como la música de cámara de Brahms (con todo derecho podríamos hablar de mística en el caso del Cuarteto de cuerda Op. 67 en si bemol mayor), que tiene la capacidad de activar en Wittgenstein sus pulsiones autodestructivas, no puede ser una música tibia y meliflua: su intensidad conduce epekeina tes ousías, más allá de la esencia, de la entidad, del ser mismo. De ahí que Wittgenstein la considere fascinante, aplastante, arrolladora o grandiosa (überwältigend). La música de Mendelssohn, pese a su excelencia y perfección, no pasa de ser un ejercicio de virtuosismo - Wittgenstein dirá de ella que es un simple arabesco musical. Ni siquiera Wagner tiene la fuerza de pensamiento que Wittgenstein atribuye a Brahms: "El drama en Wagner tampoco es drama, sino una seriación de situaciones que 
están como ensartadas en un hilo, que a su vez ha sido inteligentemente hilado, pero que carece, lo mismo que los motivos y las situaciones, de inspiración" (Wittgenstein 2009d, 603). Los movimientos conductores o motivos temáticos que sirven de soporte al drama wagneriano ni son condición necesaria ni suficiente para crear una genuina obra de arte según Wittgenstein. Porque es del todo improbable que la obra de arte total pueda enhebrarse únicamente a partir de una técnica miniaturística a base de fragmentos musicales recurrentes, secuencias melódicas o sonidos sueltos. Quizá no sea difícil conservar en la memoria los motivos conductores de Tannhäuser y Lohengrin, que son claros tanto rítmica como melódicamente. En El anillo del nibelungo el editor de los Bayreuther Blätter, Hans von Wolzogen, cita no menos de noventa Leitmotive que identifica y a los que da nombre, siendo, pese a todo, muy poco definidos. Por eso escribe Wittgenstein a propósito del ciclo del Anillo wagneriano: "los únicos pasajes imperecederos \& auténticos del «Anillo» son los épicos, en los que texto o música narran. Y por eso las palabras más impresionantes del «Anillo» son las de las instrucciones escénicas" (Wittgenstein 2009c, 239). El mérito de Wagner reside en haber asociado mito con motivo conductor. Esta asociación por sí sola, sin embargo, muestra el talento de Wagner, no su genio. En sus anotaciones de 1942 Wittgenstein escribe:

"Genio es lo que nos hace olvidar el talento del maestro.

Genio es lo que nos hace olvidar la destreza.

Donde el genio es delgado, se puede transparentar la destreza. (El preludio de Los maestros cantores.)

Genio es lo que hace que no podamos ver el talento del maestro.

Sólo donde el genio es delgado, puede verse el talento" (Wittgenstein 2009d, 606).

Wagner, en contra de lo que considera Spengler y, sobre todo, Weininger - "Wagner, el más grande hombre después de Cristo" (Weininger 1985, 337)-, es un autor que, como Mahler, tiene enormes talentos, habilidades o destrezas. No obstante, está privado de genio. 
En su recensión de Tannhäuser, Baudelaire explica que escuchar la música ardiente de Wagner es, además de una experiencia emparentada con las visiones y les vertigineuses conceptions de l'opium, algo mágico. De las notas de Wittgenstein podemos concluir su sospecha de que la música de Wagner no sea sino precisamente eso: magia, prestidigitación, hechizo, encantamiento. Paul Engelmann recuerda que, si en sus reuniones disfrutaban de las interpretaciones de Fritz Zweig al piano o al órgano - interpretaciones que giraban en torno a las obras de los «grandes»: de Mozart, Schumann, Schubert, Brahms, etc.-, en sus conversaciones se maldecía al que consideraban "destructor de la música y de la cultura, Richard Wagner, que entonces era el pope intocable universal. Wittgenstein no maldecía, pero tampoco tenía mucho en contra de que se hiciera" (Wittgenstein-Engelmann 2009, 117). Pese a todo, y por muy poca simpatía que tuvieran hacia la obra wagneriana, tanto unos como otros reconocían el mérito de haber relacionado mito y Leitmotiv: aquí radicaría la maestría de Wagner. Sin embargo, Wagner no es para Wittgenstein uno de esos grandes soles que regresan cíclicamente y que conforman ellos mismos el centro de una cultura - sí lo es Goethe; también Möricke, Lessing, Mozart o Beethoven. Pero, ¿y Brahms?

\section{Claroscuros}

La música de Beethoven supone para los compositores más inquietos de la juventud germana del siglo XIX y, en buena medida, del XX, el barniz pétreo que recubre las acciones de quienes quieren revitalizar con adolescente entusiasmo, fuerza y arrebato, la marchita vida de los hombres. Así, escribir una sonata para piano, un cuarteto de cuerda o una sinfonía equivale a ser medido por el rasero de las composiciones de Beethoven que, de algún modo, suponen el modelo o arquetipo al que un músico debe plegarse. Brahms, que venera a Beethoven (en su casa de la Karlgasse humildemente decorada apenas sí hay un retrato de Bach y un busto del músico renano), carga sobre sus hombros con una responsabilidad doble: la de componer, no sólo una sinfonía que esté a la altura del devenir interno de la sinfonía beethoveniana, sino y sobre 
todo una obra que cumpla con las expectativas despertadas por el artículo de Schumann en la Neue Zeitschrift für Musik, donde proclama a Brahms como el «elegido», el verdadero apóstol, ese músico alrededor de cuya cuna han velado las gracias y los héroes (Platt 2003, 310). Esta responsabilidad casi desborda la capacidad creativa de Brahms, que invertirá más de quince años en componer su primera sinfonía. En su correspondencia el peso, la obligación y la exigencia se dejan sentir en varias ocasiones. Wittgenstein, que reúne los atributos que, según Gracián, hacen un prodigio (ingenio fecundo, juicio profundo y gusto jocundo) parece aprehender la frágil ambivalencia musical y el espíritu autocrítico de Brahms - "a veces me entristece no saber cómo componer, cómo crear” (Brahms 2010, 31), escribe en una ocasión a Clara Schumann. Para Wittgenstein, Brahms y, también, Wagner, "han imitado a Beethoven; pero lo que en él era cósmico, se convierte en ellos en terrenal" (Wittgenstein 2009d, 642). Wittgenstein comprende las enormes dificultades que acarrea el proceso creativo. Sin embargo, recrimina a Brahms el que no haya sido capaz de llegar hasta al final en sus composiciones, el no haber tenido el arrojo de explotar su superabundancia armónica y melódica y haberse quedado, en último término, a medio de camino de ninguna parte. La amonestación parece dirigirse, principalmente, a la preparación de las partituras para cada uno de los instrumentos de sus obras sinfónicas.

"Cuando se le reprocha a la instrumentación de Brahms carencia de sentido del color hay que decir que la falta de color ya está en la temática de Brahms. Los temas son ya en blanco y negro, como los de Bruckner son ya en color; aunque Bruckner, de hecho, por cualquier motivo, los hubiera puesto por escrito sólo en un sistema de modo que no supiéramos nada de una instrumentación bruckneriana.

Así que podría decirse: entonces todo está en orden, puesto que a temas en blanco y negro corresponde una instrumentación en blanco y negro (incolora). Creo que precisamente aquí está el punto débil de la instrumentación brahmsiana, a saber, que a menudo no es, sin embargo, declaradamente en blanco y negro" (Wittgenstein 2009c, 241). 
Lo primero que llama la atención en el texto citado es la comparación, en absoluto fortuita, entre la obra de Brahms y Bruckner. Es conocida la polémica suscitada entre ambos - polémica que, como pone de manifiesto Margaret Notley en su ensayo Lateness and Brahms, va más allá del plano estético: si a Brahms se le asocia al establishment liberal, Bruckner está ligado al movimiento Pan-Germánico y al antisemitismo del partido Social-Cristiano liderado por Karl Lueger. La disputa tiene todos los ingredientes de una sórdida radionovela. Ciertamente, a Brahms le llueven las críticas desde las páginas del Wiener Salonblatt de Hugo Wolf. Sin embargo, los ataques de Hanslick, Kalbeck y Dömpke a Bruckner no son menos furibundos. Éste último llega a dirigirse a Bruckner con el apelativo de Untermensch (Notley 2007, 16). Y no sólo eso: en su biografía sobre Brahms, Kalbeck se hace eco de una carta enviada por aquél a Elisabet von Herzogenberg en la que afirma que ni se pude hablar sobre las composiciones de Bruckner ni sobre él como persona. "Er ist ein armer verrückter Mensch", escribe Brahms: es un pobre loco (Kalbeck 1913b, 408). Brahms rechaza la densa sonoridad de las sinfonías de Bruckner: tanto el cromatismo atropellado como su predilección por la grandiosidad y la monumentalidad son características tonales, según Brahms, de una música en demasía influenciada por la formación católica de Bruckner. La arquitectónica compositiva y la lógica que soportan sus sinfonías son, asimismo, despreciadas por Brahms. Por ello no parece casual la comparación de Wittgenstein: frente a los diferentes colores de la paleta de Bruckner, la instrumentación brahmsiana es incolora - en blanco y negro-. Esto, contra lo que podría pensarse, no supone desventaja alguna. Wittgenstein mismo escribe en una ocasión que "la sabiduría es gris" (Wittgenstein 2009d, 623). Si el saber brota de la mezcla entre el blanco y el negro, la música de Brahms está inicialmente emparentada con la sabiduría - porque, para Wittgenstein, también la música es un saber que enseña, tanto o más que las ciencias. Lo que ocurre es que Wittgenstein percibe en Brahms una falta que coincide, en buena medida, con lo que algunos críticos le reprochan al compositor de Hamburgo (desde Wagner a George Bernard Shaw): vivacidad, éxtasis, abundancia, voluntad de límite. Nietzsche escribe: Brahms "no crea desde la plenitud, está sediento de 
ella" (Nietzsche 2005, 54). Y si este no es el sentido de las palabras de Wittgenstein, en cierto modo coincide con él. Brahms lleva a cabo como ningún otro el ideal estético que propone Schiller; a saber: que la música ha de tornarse forma pura. Para Wittgenstein, sin embargo, Brahms no llega a recorrer esta senda hasta el final, sobre todo en lo tocante a la instrumentación. Por eso y, pese a que la música de Brahms, especialmente la música de cámara, conmueve a Wittgenstein por su laconismo, por sus alusiones y silencios, detecta en algunas de sus composiciones un desequilibrio entre objetivación formal e impulso subjetivo.

\section{Conclusiones}

Brahms, a quien Wittgenstein llegó a conocer personalmente y por el que sentía profunda admiración, es el último de los "grandes». Sin embargo, intuye ya en sus composiciones los ecos y reverberaciones de la atrofia espiritual que, en poco tiempo, llevará a una irreversible transvaloración de todos los valores en el mundo occidental. Como el punto de la curva en el que el sentido de su curvatura cambia, la música de Brahms representa el pináculo de una cultura que ya se desvanece -es la peligrosa dialéctica de la inflexión: culminación, pero también declive o depresión. Quizá sea este el motivo por el que Wittgenstein llegó a decir en una ocasión: [con la música de Brahms] 2puedo comenzar a oír el ruido de la maquinaria" (Monk 1997, 30).

\section{Bibliografía}

Brahms, J. 2010. Cartas. Editado por H. Gál. Barcelona: Nortesur.

Goethe, J. W. 1960. "Die Metamorphose der Pflanzen”. En Poetische Werke, tomo I. Berlín: Berliner Ausgabe.

Janik, A. y Toulmin, S. 1983. La Viena de Wittgenstein. Madrid: Taurus Kalbeck, M. 1913a. Johannes Brahms, tomo III, primera parte. Berlín: Deutsche Brahms-Gesellschaft.

Kalbeck, M. 1913b. Johannes Brahms, tomo III, segunda parte. Berlín: Deutsche Brahms-Gesellschaft. 
Malcolm, N. 2001. Ludwig Wittgenstein. A Memoir. Oxford: Oxford University Press.

Mann, T. 2009. Doktor Faustus. Vida del compositor alemán Adrian Leverkühn narrada por un amigo. Barcelona: Edhasa.

McGuiness, B. 2008. Wittgenstein in Cambridge: Letters and Documents. Editado por B. McGuiness. Oxford: Blackwell.

Monk, R. 1997. Ludwig Wittgenstein. El deber de un genio. Barcelona: Anagrama.

Nietzsche, F. 2005. “El caso Wagner. Un problema para melómanos”. En Nietzsche contra Wagner. Madrid: Siruela.

Notley, M. 2007. Lateness and Brahms. Music and Culture in the Twilight of Viennese Liberalism. Oxford: Oxford University Press.

Nyíri, J. C. 1986. Gefühl und Gefüge. Studien zum Entstehen der Philosophie Wittgensteins. Ámsterdam: Rodopi.

Platt, H. 2003. Johannes Brahms. A Guide to Research. Nueva York y Londres: Routledge.

Sanfélix, V. 2005. "Una filosofía del espíritu. Wittgenstein y la cuestión judía”. En La mente en sus máscaras. Ensayos sobre filosofía de la psicología. Coord. M. Rodríguez. Madrid: Biblioteca Nueva.

Schönberg, A. 1984. Style and Idea. Selected Writings of Arnold Schoenberg. Editado por L. Stein. Berkeley: University of California Press.

Spengler, O. 1989. La decadencia de Occidente. Bosquejo de una morfología de la historia universal, tomo I. Madrid: Espasa - Calpe.

Steiner, George. 2001. "Una lectura contra Shakespeare." En Pasión intacta: ensayos 1978 - 1995. Madrid: Siruela.

Waugh, A. 2009. The House of Wittgenstein. A Family at War. Londres: Bloomsbury Publishing.

Weininger, O. 1985. Sexo y carácter. Barcelona: Península.

Wittgenstein, L. 1980. “Tractatus logico-philosophicus”. En Schriften 1. Frankfurt: Suhrkamp Verlag.

Wittgenstein, L. 1981. Personal Recollections. Editado por R. Rhees. Oxford: Basil Blackwell. 
Wittgenstein, L. 2002. Investigaciones filosóficas. MéxicoD.F.-Barcelona: UNAM/Crítica.

Wittgenstein, L. 2003. Public and Private Occasions. Editado por J. C. Klagge y A. Normann. Londres: Rowman and Littlefield Publishers.

Wittgenstein, L. 2009a. “Diario filosófico (1914-1916)”. En Wittgenstein II. Diarios. Conferencias. Madrid: Gredos.

Wittgenstein, L. 2009b. "Lecciones y conversaciones sobre estética, psicología y creencia religiosa”. En Wittgenstein II. Diarios. Conferencias. Madrid: Gredos.

Wittgenstein, L. 2009c. "Movimientos del pensar. Diarios 19301932/1936-1937". En Wittgenstein II. Diarios. Conferencias. Editado por I. Somavilla. Madrid: Gredos.

Wittgenstein, L. 2009d. “Observaciones diversas. Cultura y valor”. En Wittgenstein II. Diarios. Conferencias. Madrid: Gredos.

Wittgenstein, L. 2009e. “Zettel”. En Wittgenstein II. Diarios. Conferencias. Madrid: Gredos.

Wittgenstein, L. y Engelmann, P. 2009. Cartas, encuentros, recuerdos. Editado por I. Somavilla. Valencia: Pre-Textos.

Zweig, M. 1987. Lebenserinnerungen. Gerlingen: Bleic 